- Demonstrates that one half of all dentists have been asked about Internet derived information by patients.

- While accepting that the Internet is a useful source of information, one third of dentists CPD PAPER suggested that such information has led to patients seeking more complex or inappropriate care.

- While the great majority of dentists use the Internet to seek information for themselves, three in four never refer patients to the Internet.

- There is an urgent need to help practitioners identify the most useful websites.

\title{
Perceptions of how the Internet has impacted on dentistry
}

\author{
I. G. Chestnutt ${ }^{1}$ and K. Reynolds ${ }^{2}$
}

\begin{abstract}
Objectives This study sought to identify how patient information on the Internet has influenced the delivery of oral care and the use practitioners themselves make of the Internet.

Methodology Data were collected via a self completed 18 item postal questionnaire, sent to a random sample of 620 dentists on the GDC register in Wales.

Results In total 457 (74\%) of the questionnaires were returned. One half of all practitioners stated that patients had asked them about material of relevance to dentistry obtained from the Internet, although in the majority of cases this happened less frequently than once a month. The most common topics enquired after were cosmetic procedures, dental amalgam and implants. A minority of dentists, 47 (11\%) viewed the Internet as a threat to the dentist-patient relationship. However, 169 (39\%) agreed information gained from the Internet had led to patients demanding inappropriate care or more complex treatment (135/31\%). Having to take time to discuss Internet material was viewed as a burden by 93 practitioners. The potential of the Internet to widen inequalities in access to oral health information was agreed upon by one third of respondents. Concerns over the quality and reliability of Internet derived information, together with a lack of knowledge of appropriate sites, prevented dentists using the Internet as an oral health education resource. However, only $18.7 \%$ claimed never to use the Internet for their own Continuing Professional Development. Access for CPD purposes was mainly from home. Of those working in general practice, 54 had their own practice website, and a further 103 said this was something they were considering. Email was used to communicate with patients by 42 dentists, mainly to make appointments.

Conclusions Views on the impact of the Internet were generally positive, but there is a long way to go before its full potential is realised.
\end{abstract}

\section{INTRODUCTION}

The development and expansion of the Internet represents one of the greatest advances in our ability to communicate and

\footnotetext{
${ }^{1 *}$ Reader and Honorary Consultant in Dental Public Health, ${ }^{2}$ Research Assistant, Dental Public Health Unit, Dental School, Heath Park, Cardiff CF14 4XY

${ }^{*}$ Correspondence to: Dr Ivor Chestnutt

Email: chestnuttig@cardiff.ac.uk

\section{Refereed paper}

Accepted 13 April 2005

doi: $10.1038 /$ sj.bdj.4813195

(๑) British Dental Journal 2006; 200: 161-165
}

disseminate knowledge and is arguably on a par with the invention of the printing press, the television and the telephone. In early 2004, 12.1 million, or 49\% of all households in the United Kingdom, could access the Internet from home. Just over one quarter of adults in Great Britain claimed to access the Internet every day or almost every day. ${ }^{1}$

The Internet has tremendous potential to influence health and health care. It will increasingly be used to educate and empower the public, by providing information on health and on health services and by supporting self-help and patient choice. ${ }^{2}$ Other future benefits of educating and informing patients via the Internet include: improving the quality and appropriateness of care; encouraging the adoption of healthy behaviours by patients; better compliance with advice, and the appropriate use of medicines. ${ }^{3}$ Furthermore, now and in the future, the Internet will, via practice based websites, constitute a central forum for communication between practices and their patients. This is already common in North America. ${ }^{4,5}$

However, while there is a considerable body of research on the impact of the Internet as it relates to medicine in general, ${ }^{6}$ there is little evidence about how the Internet is impacting on dentistry in the UK. ${ }^{7}$ The first study of dental information for patients on the Internet concluded that judicious and active support from professionals would be required to aid patients' interpretation of periodontal-related patient information sites. ${ }^{8}$ It has also recently been shown that a good deal of the Internet derived information on common oral pathologies is beyond the average UK reading age. ${ }^{9}$ As the NHS develops its information technology strategy in relation to dentistry, information is required on how best to harness the undoubted benefits of the Internet, to improve the delivery of dental care and facilitate the promotion of oral health.

\section{AIMS AND OBJECTIVES}

This study therefore sought the views of a representative sample of all dentists in Wales on two important aspects of how the Internet has impacted on dentistry, namely: how patient information on the Internet has influenced the delivery of oral care; and the use practitioners themselves make of the Internet.

Specifically the study aimed to answer the following questions:

- How frequently do dental patients seek advice on material they

have read or downloaded from the Internet?

- What topics are patients most likely to read about on the Internet? 


\begin{tabular}{|c|c|c|}
\hline Sphere of practice & No & $\%$ \\
\hline \multicolumn{3}{|l|}{ General dental practice } \\
\hline Wholly NHS & 93 & 21.3 \\
\hline Mainly NHS & 136 & 31.2 \\
\hline Mixed NHS/Private & 73 & 16.7 \\
\hline Mainly Private & 41 & 9.4 \\
\hline Wholly Private & 12 & 2.8 \\
\hline Community dental practice & 37 & 8.5 \\
\hline Hospital practice & 35 & 8.0 \\
\hline Other / not stated & 9 & 2.1 \\
\hline
\end{tabular}

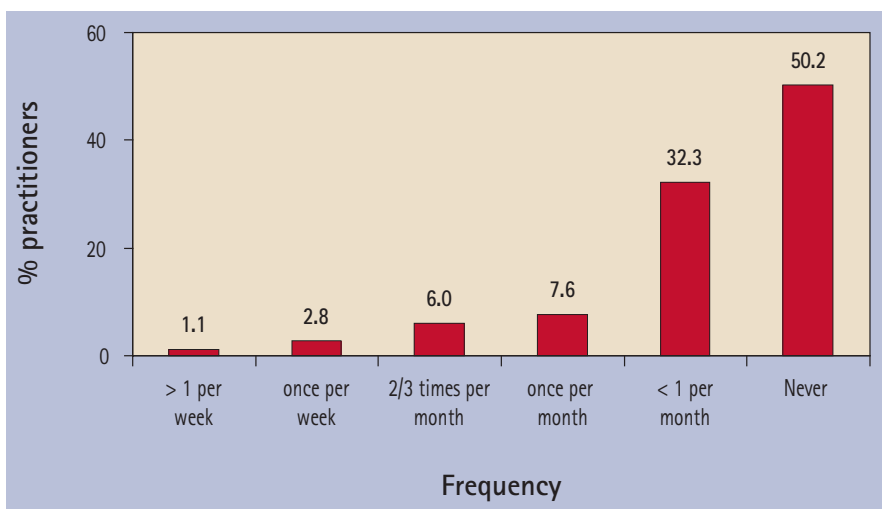

Fig. 1 The frequency with which practitioners claimed patients asked about or discussed material of relevance to dentistry that they have obtained from the Internet.

\begin{tabular}{|c|c|}
\hline Topics & $\begin{array}{l}\mathrm{N} \text { dentists claiming patients } \\
\text { asked about topic }\end{array}$ \\
\hline Cosmetic procedures & 143 \\
\hline Dental amalgam & 110 \\
\hline Dental implants & 104 \\
\hline Oral cancer & 28 \\
\hline Periodontal disease & 23 \\
\hline TMJ problems & 22 \\
\hline Mouth ulcers & 16 \\
\hline Dental caries & 4 \\
\hline Dentures & 1 \\
\hline Other topics & 69 \\
\hline
\end{tabular}

- Does the Internet foster demand for inappropriate interventions?

- Do practitioners perceive that Internet derived information has lead to unnecessary costs?

- Do practitioners perceive that Internet derived information has led to increased patient dissatisfaction?

- What are practitioners' perception of the quality and reliability of Internet derived patient education material?

- Do dentists use the Internet as an oral health education resource?

- To what extent do practitioners use the Internet to communicate directly with their patients?

- What use do practitioners make of the Internet for their own Continuing Professional Development?

\section{MATERIALS AND METHODS}

\section{The participants}

The sample frame consisted of all 1,328 dentists whose address on the Dental Register was in Wales. Of these, 650 were chosen at random by a computer. A pilot of the questionnaire was carried out using 30 of these practitioners and the main mailing was subsequently sent to the remaining 620 dentists.

\section{The questionnaire}

Data were collected using a self-administered postal questionnaire. This contained 18 items and a combination of open and closed questions were posed. Respondents were identified only by codes and attitudinal variables were measured using five point Likert scales.

\section{Data collection}

The main mailing was conducted in May 2004 and was accompanied by an explanatory letter and prepaid reply envelope. Nonrespondents were sent a further questionnaire four weeks later.

\section{Data analysis}

Completed questionnaires were coded and entered into a database and analysed by SPSS v11 (Chicago, Illinois). Frequencies were used to examine the distribution of the responses for all variables and describe sample demographics. The scales measuring attitudes were collapsed into trichotomous variables (agree/neutral/disagree). The association between variables was examined by cross-tabulations and the statistical significance of such relationships was determined by Chi-square analysis.

\section{RESULTS}

\section{The response and the respondents}

Of the 620 questionnaires mailed, 457 (73.7\%) were returned. In 21 cases the questionnaires were incomplete or the dentist was no longer at the address. Thus the results of the survey are based on 436 completed replies. Of the respondents, 291 (66.7\%) were male, and 141 (32.3\%) female, with four respondents failing to answer this question. The time since graduation covered a 50 year period, with a mean of 18.8 years. The declared sphere of practice of those returning the questionnaire was as illustrated in Table 1 . General practice accounted for $81.4 \%$ of respondents, the remainder being almost equally distributed between the Hospital and Community Dental Services.

\section{Perceptions of patient use of the Internet}

One half (217/49.8\%) of all practitioners responding to the questionnaire stated that patients had asked them about or discussed material of relevance to dentistry that they had obtained from the Internet. The majority of these practitioners claimed that this happened less frequently than once a month (Fig. 1). When questioned on specific topics that patients had asked about in connection with information they had downloaded from the Internet, responses were as listed in Table 2. From this it is apparent that cosmetic procedures were the most commonly enquired after topic. In the category classified as other, a vast range of topics were mentioned, including various mucosal pathologies, endodontics, orthognathic surgery, snoring devices and crowns and bridges.

\section{Perceptions of the impact of oral health related information on the Internet}

Practitioners' perceptions of the impact of oral health related information on the Internet as judged by agreement with eight specific statements are shown in Table 3. Overall, respondents' views were rather mixed. In total, 176 (40.4\%) practitioners agreed or strongly agreed that the Internet was a useful source of information on oral health for patients, and the majority of respondents, 244 (56\%), were agreed that patients were likely to misinterpret such information. In total, 135 (31\%) respondents agreed that information gained from the Internet had led to 


\begin{tabular}{|c|c|c|c|c|}
\hline $\begin{array}{l}\text { Statement } \\
\text { expressed }\end{array}$ & $\begin{array}{l}\text { Strongly agree } \\
\text { /agree }\end{array}$ & $\begin{array}{l}\text { Neither agree } \\
\text { nor disagree }\end{array}$ & $\begin{array}{l}\text { Disagree } \\
\text { /Strongly Disagree }\end{array}$ & No view \\
\hline & $N(\%)$ & $N(\%)$ & $N(\%)$ & $N(\%)$ \\
\hline $\begin{array}{l}\text { The Internet is a useful source of information on } \\
\text { oral health for patients }\end{array}$ & $176(40.4)$ & $207(47.5)$ & 36 (8.3) & $17(3.9)$ \\
\hline $\begin{array}{l}\text { Information gained from the Internet has led to } \\
\text { patients demanding more complex dental treatments }\end{array}$ & 135 (31.0) & $190(43.6)$ & 94 (21.6) & $17(3.9)$ \\
\hline $\begin{array}{l}\text { Information gained from the Internet has led to } \\
\text { patients demanding inappropriate dental care }\end{array}$ & 169 (38.8) & $156(35.8)$ & $94(21.6)$ & $17(3.9)$ \\
\hline $\begin{array}{l}\text { Having to take time to talk to patients about information } \\
\text { that they have obtained from the Internet is a burden }\end{array}$ & 93 (21.3) & $163(37.4)$ & 161 (36.9) & $19(4.4)$ \\
\hline $\begin{array}{l}\text { I feel adequately prepared to guide patients in the use } \\
\text { of health information obtained from the Internet }\end{array}$ & 163 (37.4) & $134(30.7)$ & 122 (28.) & $17(3.9)$ \\
\hline $\begin{array}{l}\text { Patients are likely to misinterpret information on } \\
\text { oral health gleaned from the Internet }\end{array}$ & $244(56.0)$ & 143 (32.8) & $32(7.3)$ & $17(3.9)$ \\
\hline $\begin{array}{l}\text { The Internet has the potential to widen inequalities in } \\
\text { access to oral health information }\end{array}$ & 145 (33.3) & $195(44.7)$ & 80 (18.3) & $16(3.7)$ \\
\hline $\begin{array}{l}\text { The Internet represents a threat to the 'dentist-patient } \\
\text { relationship' }\end{array}$ & 47 (10.8) & $168(38.5)$ & 205 (47.0) & $16(3.7)$ \\
\hline
\end{tabular}

patients demanding more complex dental treatments. A slightly higher proportion, 169 (38.8\%) reported that patients had demanded inappropriate care.

With regards to discussing information from the Internet, a minority of respondents, 93 (21.3\%), agreed this as a burden, although a greater number $163(37.4 \%)$ felt inadequately prepared to discuss such information. Only $47(10.8 \%)$ viewed the Internet as a threat to the dentist-patient relationship.

\section{Referral of patients to the Internet as a health education resource}

Practitioners were asked how frequently they referred patients to oral health education resources on the Internet. As shown in Table 4, three quarters of all respondents claimed that they never referred patients to such sources. Of the 96 respondents who claimed to refer patients to the Internet, the majority, $61 \mathrm{did}$ so less frequently than once a month. In response to an open question on which sites they referred patients to, the most commonly quoted site was the British Dental Association's site, albeit, this was stated by only 17 respondents. No other sites were mentioned by more than two or three respondents and included NHS Direct, the American Dental Association website, the Eastman oral medicine site, bbc.co.uk and the Straumann implant site. Generic search engines were referred to by six practitioners and one individual referred patients to their own practice website.

\section{General perceptions}

As is often the case in questionnaire surveys, some of the most interesting comments came in response to the general open question: "Are there any further points that you would like to make in relation to the role of the Internet in patient education and oral health promotion?' Eighty-four dentists responded to this question and a variety of themes were discussed.

While agreeing on the benefits of the Internet with regards to patient education, respondents expanded on their perceptions of the influence of the Internet. Difficulty in identifying appropriate sites that provide authoritative, but patient friendly information was commented on by many practitioners. Comments such as:

'It would be useful to have some well organised, reliable information to refer patients to' and 'If I knew of some good websites to refer patients to I would do so. As I do not know of any quality websites I avoid the subject.' were typical of the views expressed by many.

Other concerns centred on the quality of information available and patients' ability to interpret such information. Correcting patient misunderstanding of information obtained from the internet was seen as a difficulty by one respondent who stated:

'I have personally found a lot of the information to be inaccurate, which can lead to having to go into long explanations and discussions.'

The perception of 'a little knowledge being a dangerous thing' when it came to patients obtaining information from the Internet, was raised by some respondents.

A related issue concerned the potential of the Internet to raise unrealistic expectations in treatment outcomes, particularly with regard to cosmetic and orthognathic procedures.

Access issues for some sections of the population were also mentioned. One practitioner, working in the Community Dental Service, commented:

'...we deal with a large proportion of patients whose parents are often illiterate, let alone computer literate, and adults with special needs who are unable to access or utilise computers'.

Age was also commented on as an issue, both for patients and practitioners. Respondents recognised that younger patients were more likely to access the Internet and that this medium would assume increasing importance over time. A few practitioners, who stated that they were nearing retirement, commented that the Internet had not impacted greatly on them or their patients. Lack of computer skills was a disincentive to their own computer use or referral of patients to Internet based material.

Finally two practitioners raised the subject of the medico-legal implications of the Internet, either in referring patients to particular sites, or in communicating with patients via electronic means.

\section{Practitioners own use of the Internet}

The final stage of the questionnaire enquired after practitioners' own use of the Internet.

Overall 71 practitioners reported that their practice/clinic had its own website. There was no significant relationship between time since qualification, in terms of length of time qualified in quartiles, and practices having their own website. Considering those working in the General Dental Service, 54 of 355 practitioners (15.2\%) had their own practice website. However, amongst those general dental practitioners who did not at present have a practice website, 103 said that this was something that they were considering.

In total 42 of the 436 respondents claimed that they communicated with patients by email. Of these 31 used email to make appointments, 12 to send recall notices with just 10 claiming that 


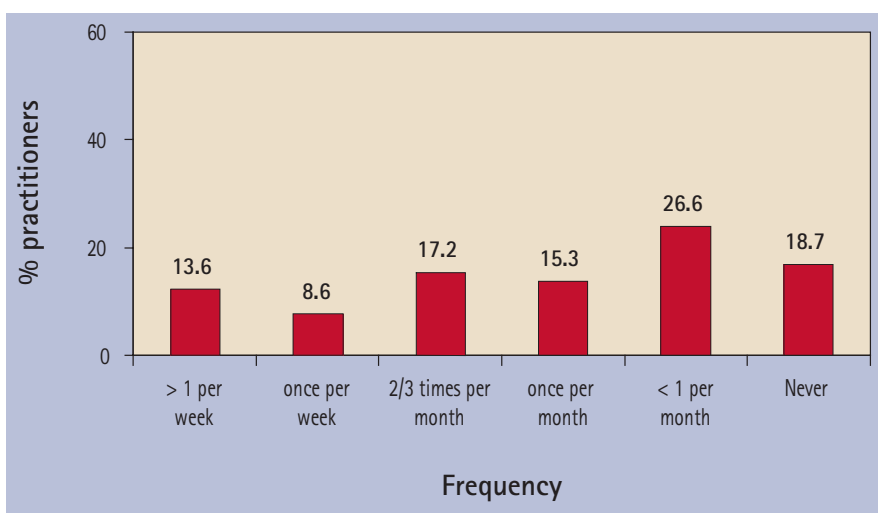

Fig. 2 Frequency with which practitioners claimed to use the Internet for their own Continuing Professional Development.

Table 4 Frequency with which dentists claimed to refer patients to the
Internet
\begin{tabular}{lll}
\hline Frequency & N & $\%$ \\
\hline More than once a week & 7 & 1.6 \\
\hline Once a week & 4 & 0.9 \\
\hline Two or three times a month & 16 & 3.7 \\
\hline Once a month & 8 & 1.8 \\
\hline Less frequently than once a month & 61 & 14.0 \\
\hline Never & 327 & 75.0 \\
\hline Not stated & 13 & 3.0 \\
\hline
\end{tabular}

they used email to market their practice/clinic.

Continuing professional development and the Internet

The frequency with which respondents claimed to access the Internet to aid their own Continuing Professional Development (CPD) is shown in Figure 2. Just 18.7\% claimed never to access the Internet for this purpose. Use was significantly related to time since qualification with a significantly greater proportion $(84.4 \%, p<0.001)$ of the quartile most recently qualified using the Internet for CPD purposes, compared with $66 \%$ of the quartile qualified for the longest time. Of the 340 dentists who said that they used the Internet for CPD, the great majority, 277, stated that they access the Internet most commonly at home, 28 access the Internet mainly at work, while 35 reported using the Internet equally at home and at work.

\section{DISCUSSION}

Although there has been considerable research into the impact of the Internet on medical care in general, its impact on dentistry has been less intensively examined. A recent survey in an English Strategic Health Authority concluded that only 45\% of practices had access to the Internet. ${ }^{10}$ Walmsley and colleagues have recently reported on the use of the Internet within a UK dental school, but perceptions of how it has to date influenced the wider dental community is unknown, hence the current study. ${ }^{11}$ With 436 valid responses, this questionnaire was completed by one third of all dentists in Wales, across all branches of the profession. As such, the results can be viewed as a true representation of the how the profession viewed the Internet in mid-2004, and although restricted to the Principality, is likely to mirror the position in many other parts of the UK.

It is apparent that although one half of all respondents have been asked about Internet derived information by patients, this occurs relatively infrequently (Fig. 1). In his book The Resourceful Patient, Gray describes what he sees as the decline in sapiential authority, that is, power derived from knowledge, currently affecting the medical profession. ${ }^{12}$ He argues that although some patients were always more intelligent and better educated than some clinicians, it is only recently that they have found the confidence to challenge clinicians. This suggests the potential for a changed relationship between healthcare professionals and their patients. Anderson and colleagues, in a review of the impact of the Internet on the physician-patient relationship, suggest that disagreements on a course of medical action may cause friction. ${ }^{13}$ In the current study, only a minority of respondents viewed the Internet as a threat to the dentist-patient relationship. However, the proportion of respondents agreeing that the Internet has led to patients demanding more complex or inappropriate care, or indeed who view having to take time to talk to patients about information from the Internet as a burden, gives some idea of potential conflicts in this area.

Looking to the future, one of the hopes that greater access to Internet derived information will bring is to amplify the patient's role in managing their own health, by assuming more responsibility for improving and maintaining their oral health and being proactive in decisions about their dental care. However, if this is to happen, then patients must have access to high quality and appropriate information. The very low numbers of dentists routinely referring patients to information on the Internet (Table 4), demonstrates the need to expand activities in this area. Knowing where to refer patients for appropriate help on the Internet was viewed as a major obstacle. In the open comments, many practitioners cited this as a problem and a number requested help from the authors in this area. It would appear that despite developments such as NHS Direct, and other patient orientated sites, the need for a central resource to which patients can be referred is lacking.

A further barrier is concern over the quality of information posted via the Internet, a well recognised phenomenon. ${ }^{8,14}$ This was reinforced by some respondents having difficulties finding information for their own use or having discovered information, being sufficiently concerned about its accuracy, to be discouraged from referring patients to the Internet. However, despite these reservations, $40.4 \%$ agreed or strongly agreed that the Internet was a useful source of information for patients.

Practitioners made good use of the Internet for their own Continuing Professional Development (CPD), and as might be expected this was greatest amongst recent graduates. In remote and rural areas where a large proportion of dentists work in single handed practices, Internet delivered CPD provides a useful addition to the postgraduate education armamentarium. It is encouraging that less than one in five dentists reported not using the Internet for CPD purposes. That the Internet is most commonly accessed from home, reflects the state of IT development in many dental practices in Wales and the fact that much CPD activity is likely to occur outside office hours.

Finally, although some dentists claimed to use the Internet to make appointments or send recall notices, the small numbers involved suggest that it will be some time before the full benefits of e-communication offered by the Internet will be realised in terms of the organisation and management of many dental practices.

\section{CONCLUSIONS}

Overall, practices had a generally positive outlook with regards to the role of the Internet in the provision of information to patients. However, concerns over the quality of information and lack of knowledge of appropriate sites to which patients could be referred, currently limit practitioners' use of the Internet as an educational resource. There is a need to facilitate and develop practitioners' use of the Internet to maximise its potential benefits to patients. In contrast, four out of five dentists access the Internet for their own CPD. A limited number have their own practice website and even fewer currently use the Internet to communicate with patients. However, many of those practices who do not currently have a practice website, plan to do so in the future. 
This study suggests that the impact of the Internet on dentistry is on the whole positive, but there is a long way to go before its potential benefits are realised in full.

The authors wish to express their sincere thanks to all those who completed the questionnaires. This study was funded by a grant form the Chief Medical Officer, Wales Assembly Government, whose assistance is acknowledged gratefully.

1. Office for National Statistics. http://www.statistics.gov.uk/CCI/nugget.asp?ID=8\& Pos $=3 \&$ ColRank=1\&Rank=160 Accessed 27/07/04

2. Eysenbach G. Consumer health informatics. BrMed J 2000; 320: 1713-1716.

3. Powell J A, Darvell M, Gray J A M. The doctor, the patient and the World Wide Web: how the Internet is changing healthcare. JR Soc Med 2003; 96: 74-76.

4. Schleyer TK L, Spallek H, Torres-Urguidy M H. A profile of current Internet users in dentistry. J Am Dent Assoc 1998; 129: 1748-1753.

5. Smith K. The financial wonders of electronic patient communication. Dent Econ 2004: 94: 92-96.
6. Diaz J A, Griffith R A, Ng J J et al. Patients' use of the Internet for medica information. J Gen Intern Med 2002; 17: 180-185.

7. Chestnutt I G. Patient information on the Internet - what are the issues? Comm Dent Health 2001; 18: 205-206.

8. Chestnutt | G. The nature and quality of periodontal related patient information on the World Wide Web. Br Dent J 2002; 193: 657-659.

9. Chestnutt I G. Internet-derived patient information on common oral pathologies: Is it readable? Primary Dental Care 2004; 11: 51-54

10. John J H, Thomas D, Richards D. Questionnaire survey on the use of computerisation in dental practices across the Thames Valley Region. Br Dent J; 195: 585-590.

11. Walmsley $A D$, White $D A$, Eynon $R$, Summerfield $L$. The use of the Internet within dental school. Eur J Dent Educ 2003; 7: 27-33.

12. Gray M. The resourceful patient. Http://www.resourcefulpatient.org/text/14.htm Accessed 19/03/03.

13. Anderson J G, Rainey M R, Eysenbach $G$. The impact of CyberHealthcare on the physician-patient relationship. J Medical Systems 2004; 27: 67-84.

14. Dental Watch. www.dentalwatch.org Accessed 01/10/04. 